\title{
Owls Eyes in the Left Atrium
}

\author{
Vithalkumar Malleshi Betigeri*1 and Akhlesh Singh Tomar ${ }^{2}$ \\ ${ }^{1}$ Department of Cardiovascular and Thoracic Surgery, GIPMER, India \\ ${ }^{2}$ Department of Anesthesia, GIPMER, India
}

Submission: May 24, 2017; Published: June 01, 2017

*Corresponding author: Vithalkumar M Betiger, Professor, Department of Cardiovascular and Thoracic Surgery, Room No: A-113, Academic Block, GIPMER, Bahadur Shah Zafar Marg, Near Delhi gate, New Delhi, India- 11002, Tel: +91-9718598645; Email: vithalkumarmb@gmail.com

\begin{abstract}
"Owls eyes" appearances in cardiac surgery have been described in literature in conditions of infiltrative cardiomyopathies, during pulmonary vein visualisation for catheter ablation of symptomatic atrial fibrillation. Unlike in the literature, an intraoperative transesophageal echocardiogram while evaluating the cardiac structures in our adult case of chronic rheumatic heart disease with treated infective endocarditis showed "Owls eyes" appearance in left atrial chamber which were due to specific pathology of posterior mitral leaflets involved with rheumatic disaease and findings confirmed at the operation.
\end{abstract}

Keywords: Endocarditis; Transesophageal echocardiophy; Mitral regurgitation; Mitral valve replacement

\section{Introduction}

As a non invasive tool, echocardiography has emerged over decades as an essential, standard technique for diagnosis and evaluation of structural and functional aspects of cardiac valves in pre, intra and postoperative management. Comprehensive assessment of cardiac valves pathology as a primary, as well as secondary effects can be evaluated by both transthoracic and transesophageal echocardiography tools [1]. We report unusual appearances of prolapsed posterior mitral leaflets in an intraoperative transesophageal echocardiography.

\section{Case Report}

A 35 year old male patient of known rheumatic heart disease and infective endocarditis was referred for valve replacement surgery after appropriate antibiotic therapy with transthoracic echocardiographic findings of severe mitral stenosis with mitral orifice area of $1.0 \mathrm{~cm} \mathrm{[2],} \mathrm{severe} \mathrm{mitral} \mathrm{regurgitation} \mathrm{with}$ anteriorly directed jet due to posterior mitral leaflet prolapse, severe calcified subvalvular apparatus, dilated left ventricle, mild aortic regurgitation and mild pulmonary hypertension. Intraoperative transesophageal echocardiography [HD11XE, Philips] done prior to surgical intervention confirmed the findings of transthoracic echocardiography. But while analysing all six segments of mitral valve, with small rotation of angle of the multiplane transducer between 20-30 degree, the intraoperative mid oesophageal four chamber view of the transesophageal echocardiography showed an unusual finding of membrane-like structures, looked like "Owls eyes" appearance (Figure 1) end systolic (A) and end diastolic (B) views) in the left atrium (LA), which were not seen in transthoracic echocardiography. The mid oesophageal long axis view between 120-160 degree revealed severe mitral regurgitation through the suspected perforation in P2 as well as non coapting edges.

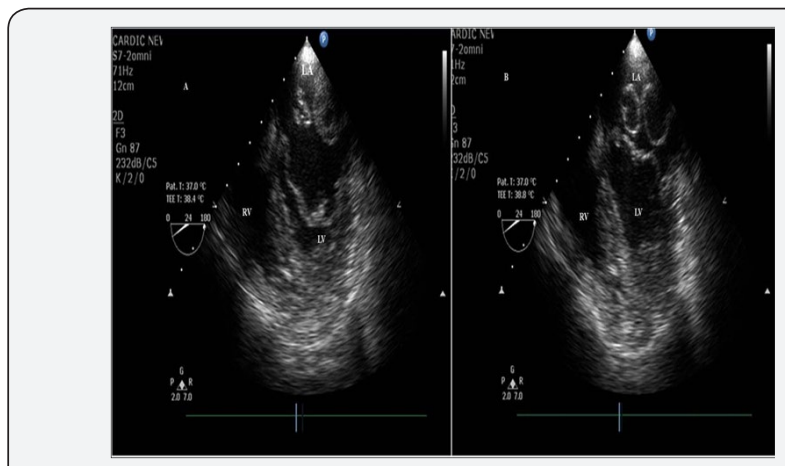

Figure 1: Intraoperative transesophageal echocardiograph showing 'Ow/s eyes' appearance in left atrium in end systolic (A), end diastolic (B) (LA: Left Atrium; LV: Left Ventricle; RV: Right Ventricle).

Intraoperatively, under cardiopulmonary bypass, aortico bicaval cannulation and antegrade cold blood cardioplagic arrest, left atriotomy (Figure 2) revealed no membrane like structures in the left atrium but instead confirmed thick and fibrosed mitral leaflets, prolapse of P1 and P3 segments of posterior mitral 
leaflet, severe commissural fusion, noncoapting leaflets edges, dilated annulus, severe calcific subvalvular agglutination with tethering to left ventricular myocardium especially of P2 along with perforation in it. Mitral valve replacement done with $33 \mathrm{~mm}$ ATS mechanical bileaflet valve (Medtronic ATS Medical Inc.MN) was uneventful. Patient is doing well at 2 year follow up.

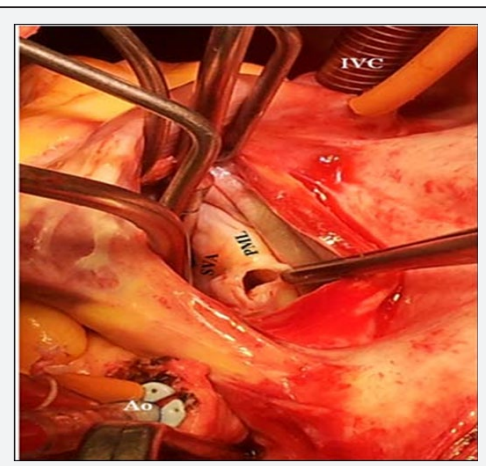

Figure 2: Left atriotomy revealing $P 1$ and $P 3$ segments of posterior mitral leaflet (PML) along with perforation in P2 segment and severe subvalvular agglutination (Ao: Aorta; IVC: Inferior Vena Cave; SVA: Subvalvular Apparatus).

\section{Discussion}

In transesophageal echocardiography, unusual findings of membrane like structures in the left atrium 2 are reported in literature due to supramitral ring, cortriatrium sinister, congenitally divided left atrium and membranes at mouth of left atrial appendages. During catheter ablation for atrial fibrillation, intracardiac echocardiography gives an accurate real time imaging of pulmonary-left atrial junction for accurate ablation wherein cross sectional plane of right pulmonary veins at level of antrum are visualised through a view called "Owls eyes" view [3]. Transthoracic view of enlarged and immobile biatria in infiltrative cardiomyopathies like amyloidosis wherein the ventricular wall, valves, interatrial septa get thickened due to amyloid deposits is also described as "Owls eyes" appearance $[4,5]$.

Unlike such appearances of "Owls eyes" in above conditions, the view of transesophageal echocardiogram in our case of severe rheumatic mitral stenosis and regurgitation, with history of treated infective endocarditis, showed typical Owls eyes appearance in the left atrium due to specific valvular pathology of posterior mitral leaflet wherein P1 and P3 segments were prolapsed along with perforation and severe subvalvular agglutination at P2 segment. Identification of such unusual findings of Owls eyes appearance of membrane in the left atrium should raise the possibility of pathology demonstrated in this case.

\section{References}

1. Kirkpatrick JN, Lang RM (2010) Surgical echocardiography of heart valves: a primer for the cardiovascular surgeon. Semin Thorac Cardiovasc Surg 22(3): 1-22.

2. Alkhulaifi AM, Altamimi O, Carr CS (2005) Left atrial membrane, left ventricular dysfunction and mitral regurgitation in an adult. Heart 91(6): 810 .

3. Saliba W, Thomas J (2008) Intracardiac echocardiography during catheter ablation of atrial fibrillation. Europace 10: 42-47.

4. Srinivasan G, Joseph M, Selvanayagam JB (2013) Recent advances in imaging assessment of infiltrative cardiomyopathies. Heart 99(3): 204-213.

5. Dubrey SW, Hawkins PN, Falk RH (2011) Amyloid diseases of the heart: assessment, diagnosis, and referral. Heart 97(1): 75-84.

\section{Your next submission with Juniper Publishers} will reach you the below assets

- Quality Editorial service

- Swift Peer Review

- Reprints availability

- E-prints Service

- Manuscript Podcast for convenient understanding

- Global attainment for your research

- Manuscript accessibility in different formats

( Pdf, E-pub, Full Text, Audio)

- Unceasing customer service

Track the below URL for one-step submission https://juniperpublishers.com/online-submission.php 